\title{
Effectiveness of Long-acting Trimetazidine in Different Clinical Situations in Patients with Stable Angina Pectoris: Findings from ODA Trial
}

\author{
Maria G. Glezer • Vladimir A. Vygodin · on behalf of ODA investigators
}

Received: January 3, 2019 / Published online: February 18, 2019

(C) The Author(s) 2019

\begin{abstract}
Introduction: Trimetazidine (TMZ) has been shown to be efficacious for angina treatment. The TMZ 80-mg formulation allows one-daily (od) dosage, which could improve symptom control and adherence.

Methods: The 3-month, observational, multicenter, prospective ODA (antianginal effectiveness and tolerability of trimetazidine modified release $80 \mathrm{mg}$ Once Daily in stable Angina patients in real-world practice) study assessed TMZ $80 \mathrm{mg}$ od effectiveness in stable angina patients with persistent symptoms despite
\end{abstract}

The full list of ODA study investigators is available in the supplementary material.

Enhanced digital features To view enhanced digital features for this article go to https://doi.org/10.6084/ m9.figshare.7628735.

Electronic supplementary material The online version of this article (https://doi.org/10.1007/s40119019-0128-3) contains supplementary material, which is available to authorized users.

M. G. Glezer $(\square)$

Department of Preventive and Emergency

Cardiology, Sechenov First Moscow State Medical

University, Moscow, Russia

e-mail: 287ast@mail.ru

\section{A. Vygodin}

Laboratory of Biostatistics, National Medical Research Center for Preventive Medicine of the

Ministry of Healthcare, Moscow, Russia therapy. Two clinical situations were compared: patients who initiated treatment with TMZ $80 \mathrm{mg}$ od (initiation group) and patients who were previously treated with TMZ $20 \mathrm{mg}$ thrice daily (tid) or TMZ $35 \mathrm{mg}$ MR twice daily (bid) and switched to TMZ $80 \mathrm{mg}$ od (switch group). Number of angina attacks, short-acting nitrate (SAN) consumption, self-reported patient daily activity, Canadian Cardiovascular Society (CCS) class, adherence to antianginal therapy, overall efficacy and tolerability were assessed.

Results: A significant decrease in weekly number of angina attacks was observed for both the initiation group ( $n=1841$ patients $)$ from $4.8 \pm 3.5$ at baseline to $0.9 \pm 1.4$ at 3 months (M3) $(P<0.001)$, and the switch group ( $n=1216$ patients) from $4.4 \pm 1.3$ at baseline to $0.9 \pm 1.3$ at M3 $(P<0.001)$. Significant reduction in SAN consumption and improvement in CCS class were observed for both groups. Adherence to antianginal therapy improved in both groups at 1 month (M1) and M3. Overall effectiveness of TMZ $80 \mathrm{mg}$ od was rated by physicians as "very good" $(68 \%$ initiation group, 70\% switch group), "good" (31\% initiation group, $29 \%$ switch group), "moderate" (1\%, both groups) or "poor" ( $<1 \%$, both groups). Overall tolerability of TMZ $80 \mathrm{mg}$ od was rated by physicians as "very good" (75\%), "good" $(25 \%)$ or "moderate" $(<1 \%)$ in both groups.

Conclusions: TMZ $80 \mathrm{mg}$ od, in association with other antianginal therapy, effectively reduced angina attacks and SAN consumption 
and improved physical activity and adherence to antianginal therapy both in patients initiating TMZ treatment and those switching from a bid or tid formulation.

Trial Registration: ISRCTN registry Identifier, ISRCTN97780949.

Funding: Servier.

Plain Language Summary: Plain language summary available for this article.

Keywords: Cardiology; Observational study; Real-world evidence; Stable angina; Trimetazidine

\section{PLAIN LANGUAGE SUMMARY}

Angina is a condition that affects more than 100 million patients worldwide. The drug trimetazidine has been shown to be efficacious for angina treatment. In the present study, two groups of patients were analyzed. One group started treatment with a formulation of trimetazidine that allows patients to take only one pill per day. The other group was previously treated with other trimetazidine formulations that had to be taken two or three times a day, and then switched to the once-daily treatment. In both cases, treatment with the new formulation decreased the number of angina attacks and the use of nitroglycerine. It also improved physical activity as reported by patients. Moreover, the number of patients taking their antianginal medicine as prescribed was increased. This new formulation could provide an opportunity to improve angina symptoms and increase the number of patientsfollowing their treatment.

\section{INTRODUCTION}

Angina pectoris is a common manifestation of coronary artery disease and can have a considerable impact on a patient's quality of life [1], but despite currently available therapies, it is not always satisfactorily managed [2-4].

Trimetazidine (TMZ) differs from other antianginal agents in that it acts directly at the myocardial cell level [5]. Add-on TMZ thus represents an opportunity to optimize antianginal treatment. Its efficacy in stable angina treatment, as monotherapy and in combination, has been reported in a meta-analysis of randomized clinical trials [6].

TMZ is now available as a new formulation of $80 \mathrm{mg}$ allowing once-daily (od) intake. The ODA (Anti-anginal effectiveness and tolerability of trimetazidine modified release $80 \mathrm{mg}$ Once Daily in stable Angina patients in real-world practice) study [7] assessed in a real-life setting the effectiveness and tolerability of TMZ $80 \mathrm{mg}$ od, as well as patient adherence to antianginal treatment, in chronic stable angina patients with persistent symptoms despite therapy. Herein, we report an additional analysis of the ODA study, in patients initiating treatment with TMZ $80 \mathrm{mg}$ od and in patients switching to TMZ $80 \mathrm{mg}$ od from previous treatment with TMZ $20 \mathrm{mg}$ tid (thrice daily) or TMZ $35 \mathrm{mg}$ MR bid (twice daily).

\section{METHODS}

ODA was a 3-month observational, multicenter, prospective study in 3066 stable angina patients with persistent symptoms despite therapy, conducted in Russia from March 2017 to June 2017 in a real-world clinical setting. The methods and main findings of this study have been previously reported [7].

Patients were treated in line with current recommendations for coronary artery disease management. Inclusion of patients into the study was exclusively determined by the decision of the physician regarding medical meaningfulness and indication for treatment with TMZ od $80 \mathrm{mg}$. Non-inclusion criteria were detailed previously [7].

For the analyses presented herein, patients for whom information on previous treatment with TMZ was available $(n=3057)$ were divided into two groups: (i) one group of patients who had not been previously treated with TMZ and initiated treatment with TMZ $80 \mathrm{mg}$ od (initiation group) and (ii) one group of patients who were previously receiving treatment with either TMZ $20 \mathrm{mg}$ tid or TMZ $35 \mathrm{mg}$ MR bid and then switched to treatment with TMZ $80 \mathrm{mg}$ od (switch group). Of the 3066 patients of the ODA 
study population, nine patients were excluded from this analysis, because it was not possible to classify them into one of the two groups (initiation or switch), due to lack of information on previous use of TMZ.

Data were collected at three visits: at baseline, at 1 month (M1) and at 3 months (M3). At each of the study visits, data were collected on the number of angina attacks, consumption of short-acting nitrates (SAN) within the week prior to the visit, evaluation of Canadian Cardiovascular Society (CCS) classification, patient self-assessment of their daily physical activity, and adherence. At the last study visit, a general assessment of tolerability and effectiveness of TMZ $80 \mathrm{mg}$ od therapy was provided by physicians (rated as 'very good', 'good', 'moderate' or 'poor').

For self-assessment of physical activity, patients were asked to rate how angina impacted their daily activity on a scale of 1 to 10 (1no limitations, 10-very marked reduction). Answers were categorized into five categories: no limitation (0), slight limitation (1-2), moderate limitation (3-4), substantial limitation (5-7), and very marked reduction (8-10).

Adherence to antianginal therapy was assessed by using a previously published six-item questionnaire [8], with the following definitions: good adherence-patient responded "NO" to all questions; moderate adherencepatient responded "YES" to 1-2 questions; nonadherence-patient responded "YES" to three or more questions. As a part of the assessment of adherence to $\mathrm{TMZ}$, patients were asked to rate how satisfied they were with TMZ therapy, on a scale of 1 -not satisfied, to 10-very satisfied, at M1 and M3.

\section{Compliance with Ethics Guidelines}

All procedures performed in studies involving human participants were in accordance with the ethical standards of the institutional and/or national research committee and with the 1964 Helsinki Declaration and its later amendments or comparable ethical standards. Informed consent was obtained from all individual participants included in the study. This study was approved by the Interuniversity Ethical Committee, Moscow.

\section{Statistical Analysis}

A descriptive statistical analysis was performed, assisted by SAS software, version 9.1. Patients were analyzed if they had valid data from all visits. All parameters were analyzed using descriptive statistics methods. The number of patients, mean value, standard deviation, minimum and maximum value or proportion by category were specified for each parameter. Differences in the numbers of angina pectoris episodes and in the necessity to use antianginal drugs were evaluated by the Wilcoxon's signedrank test. A $p<0.05$ was considered to be significant. The dynamics of the parameters analyzed from visit to visit (i.e., for the blood pressure, the efficacy of therapy etc.) were studied using both Wilcoxon signed-rank test and Student's paired $t$ test.

\section{RESULTS}

In the present analysis, the ODA study [7] population was divided into two groups: the initiation group, comprising 1841 patients who initiated treatment with TMZ $80 \mathrm{mg}$ od, and the switch group, comprising 1216 patients previously treated with TMZ $20 \mathrm{mg}$ tid $(n=84$ patients) or TMZ $35 \mathrm{mg}$ MR bid ( $n=1132$ patients) and who switched to treatment with TMZ $80 \mathrm{mg}$ od.

Demographic and baseline characteristics are summarized in Table 1. The proportion of patients with class II angina was higher in the initiation group (57.6 vs. $52.3 \%$ in the switch group), while the proportion of those with class III angina was higher in the switch group (30.0 vs. $26.0 \%$ in the initiation group). With regard to medical history, a higher proportion of patients in the switch group had previous MI (32.8 vs. $27.1 \%$ in the initiation group), percutaneous coronary intervention/coronary artery bypass grafting (39.1 vs. $17.1 \%$ in the initiation group), and diabetes mellitus (22.0 vs. $19.7 \%$ in the initiation group). Patients in the initiation group had a higher average baseline SBP (142.0 
Table 1 Demographics and baseline characteristics of the initiation and switch groups

\begin{tabular}{|c|c|c|}
\hline & Initiation group ( $n=1841$ patients) & Switch group ( $n=1216$ patients) \\
\hline Men, $n(\%)$ & $897(48.7 \%)$ & $570(46.9 \%)$ \\
\hline Age, years $\pm S D$ & $62.8 \pm 7.5$ & $62.9 \pm 7.2$ \\
\hline Age $>65$ years, $n(\%)$ & $838(45.5 \%)$ & $554(45.6 \%)$ \\
\hline \multicolumn{3}{|l|}{ CCS class, $n(\%)$} \\
\hline Class I & $302(16.4 \%)$ & $215(17.7 \%)$ \\
\hline Class II & $1060(57.6 \%)$ & $636(52.3 \%)$ \\
\hline Class III & $479(26.0 \%)$ & $365(30.0 \%)$ \\
\hline \multicolumn{3}{|l|}{ Medical history, $n(\%)$} \\
\hline History of MI & $499(27.1 \%)$ & $399(32.8 \%)$ \\
\hline $\mathrm{PCI} / \mathrm{CABG}$ & $315(17.1 \%)$ & $476(39.1 \%)$ \\
\hline Hypertension & $1602(87.0 \%)$ & $1005(86.7 \%)$ \\
\hline Stroke & $136(7.4 \%)$ & $111(9.1 \%)$ \\
\hline Diabetes mellitus & $362(19.7 \%)$ & $267(22.0 \%)$ \\
\hline Peripheral artery disease & $259(14.1 \%)$ & $191(15.7 \%)$ \\
\hline Atrial fibrillation & $207(11.2 \%)$ & $143(11.8 \%)$ \\
\hline Asthma, COPD & $138(7.5 \%)$ & $86(7.1 \%)$ \\
\hline \multicolumn{3}{|l|}{ Clinical parameters } \\
\hline $\mathrm{SBP}, \mathrm{mmHg} \pm \mathrm{SD}$ & $142.0 \pm 16.2$ & $139.9 \pm 15.7$ \\
\hline $\mathrm{DBP}, \mathrm{mmHg} \pm \mathrm{SD}$ & $85.3 \pm 9.2$ & $85.4 \pm 10.8$ \\
\hline $\mathrm{HR}, \mathrm{bpm} \pm \mathrm{SD}$ & $74.3 \pm 9.3$ & $74.6 \pm 8.9$ \\
\hline \multicolumn{3}{|l|}{ Medication, $n$ (\%) } \\
\hline Statins & $1212(65.8 \%)$ & $900(74.0 \%)$ \\
\hline Beta-blockers & $1519(82.5 \%)$ & $1012(83.2 \%)$ \\
\hline Calcium channel blockers & $780(42.3 \%)$ & $515(42.3 \%)$ \\
\hline Long-acting nitrates & $517(28.1 \%)$ & $380(31.2 \%)$ \\
\hline $\mathrm{ACEi}$ & $1031(56 \%)$ & $678(55.8 \%)$ \\
\hline $\mathrm{ARB}$ & $421(22.8 \%)$ & $293(24.1 \%)$ \\
\hline Molsidomine & $57(3.1 \%)$ & $42(3.5 \%)$ \\
\hline Nicorandil & $40(2.2 \%)$ & $20(1.6 \%)$ \\
\hline
\end{tabular}

$A C E i$ angiotensin-converting enzyme inhibitors, $A R B$ angiotensin receptor blockers, $C A D$ coronary artery disease, $C C S$ Canadian Cardiovascular Society, COPD chronic obstructive pulmonary disease, $D B P$ diastolic blood pressure, $H R$ heart rate, $M I$ myocardial infarction, $N S$ non-significant, $P C I / C A B G$ percutaneous coronary intervention/coronary artery bypass grafting, $S B P$ diastolic blood pressure, $S D$ standard deviation 
Table 2 Changes in CCS class

\begin{tabular}{llllllll}
\hline CCS class & \multicolumn{2}{l}{ Initiation group, $\boldsymbol{n}(\%)$} & & \multicolumn{4}{l}{ Switch group, $\boldsymbol{n}(\%)$} \\
\cline { 2 - 3 } & Baseline & M1 & M3 & & Baseline & M1 & M3 \\
\hline Class I & $302(16.4 \%)$ & $735(40.0 \%)^{*}$ & $1256(68.3 \%)^{*, \#}$ & & $215(17.7 \%)$ & $502(41.3 \%)^{*}$ & $833(68.6 \%)^{*, \#}$ \\
Class II & $1060(57.6 \%)$ & $877(47.7 \%)^{*}$ & $486(26.4 \%)^{*, *}$ & & $636(52.3 \%)$ & $559(46.0 \%) \dagger$ & $330(27.2 \%)^{*, * \#}$ \\
Class III & $479(26.0 \%)$ & $227(12.3 \%)^{*}$ & $97(5.3 \%)^{*, 8}$ & & $365(30.0 \%)$ & $154(12.7 \%)^{*}$ & $51(4.2 \%)^{*}$ \\
\hline
\end{tabular}

CCS Canadian Cardiovascular Society, $M 1$ month 1, M3 month 3

${ }^{*} p<0.001$ vs. baseline

$\dagger p<0.05$ vs. baseline

$\# p<0.001$ vs. M1

$\& p<0.05$ vs. M1
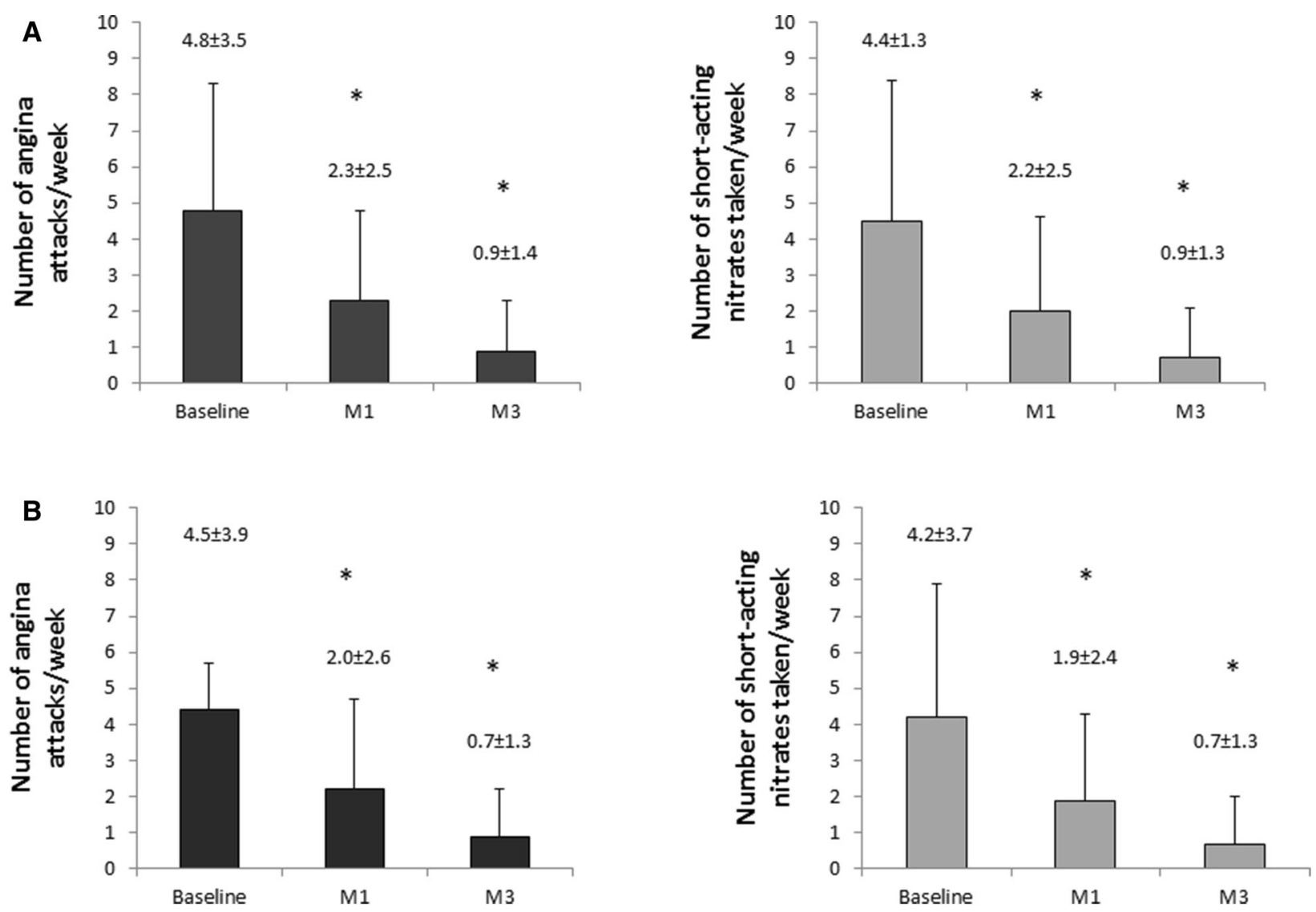

Fig. 1 Changes in mean weekly number of angina attacks and in mean number of short-acting nitrates taken per week in the initiation group (a) and in the switch group

(b) $\left({ }^{\circledR}\right.$ Servier). $M 1$ month $1, M 3$ month $3 .{ }^{*} P<0.001$ compared to baseline. Values indicated are mean \pm standard deviation

$\pm 16.2 \mathrm{mmHg}$ vs. $139.9 \pm 15.7 \mathrm{mmHg}$ in the switch group). Baseline medications were similar in both groups, with the exception of statins

(65.8\% of patients in the initiation group vs. $74.0 \%$ in the switch group). 


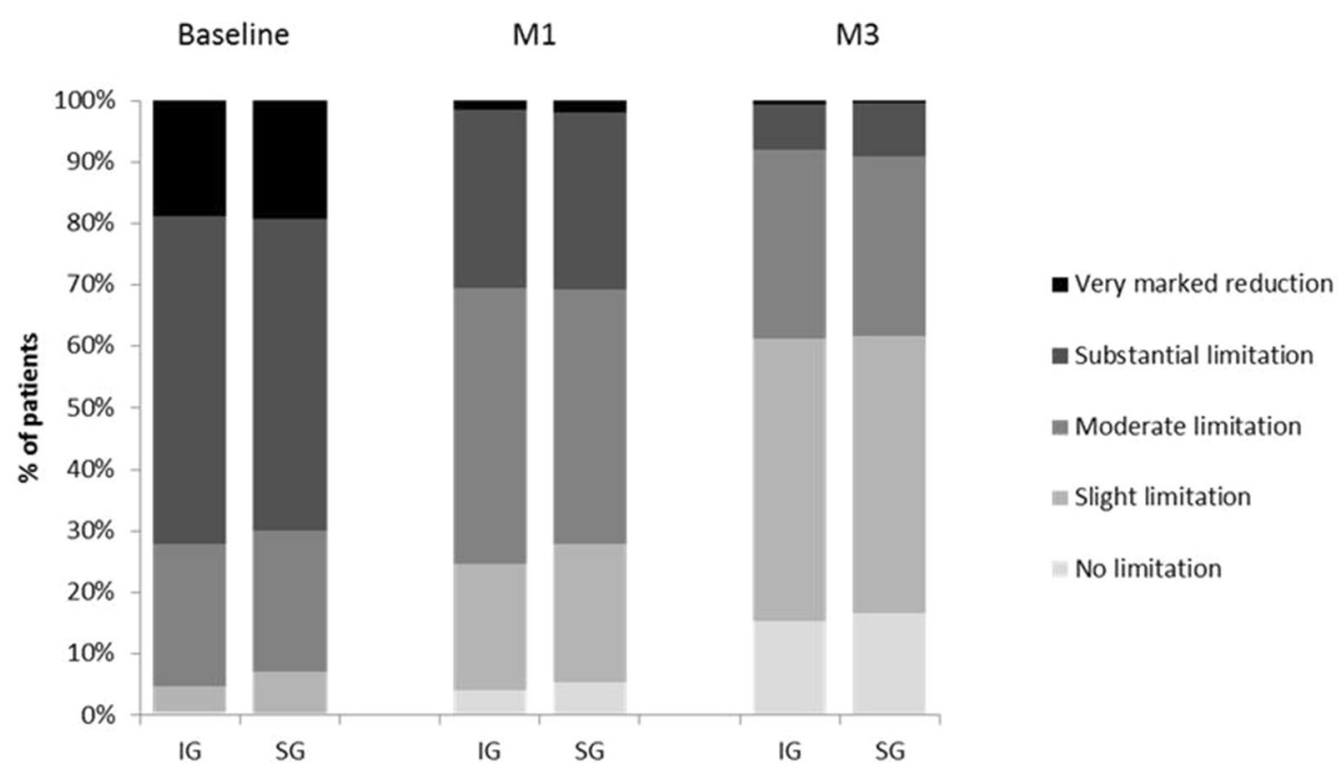

Fig. 2 Self-reported patient physical activity $\left({ }^{\circledR}\right.$ Servier). $M 1$ month $1, M 3$ month $3, I G$ initiation group, $S G$ switch group

A significant improvement in CCS class was observed in both treatment groups at M1, and a further improvement was observed at M3 (Table 2).

Treatment with TMZ $80 \mathrm{mg}$ od, whether in the initiation or the switch group, led to a significant decrease in weekly angina attack frequency from $4.8 \pm 3.5$ at baseline to $2.3 \pm 2.5$ at M1 $(P<0.001)$ and to $0.9 \pm 1.4$ at M3 $(P<0.001)$ in the initiation group (Fig. 1a), and from $4.4 \pm 1.3$ at baseline to $2.2 \pm 2.5$ at M1 $(P<0.001)$ and to $0.9 \pm 1.3$ at M3 $(P<0.001)$ in the switch group (Fig. 1b), without intergroup difference.
The average consumption of SAN per week decreased from $4.5 \pm 3.9$ at baseline to $2.0 \pm 2.6$ at $\mathrm{M} 1(P<0.001)$ and to $0.7 \pm 1.3$ at M3 $(P<0.001)$ in the initiation group (Fig. 1a), and from $4.2 \pm 3.7$ at baseline to $1.9 \pm 2.4$ at M1 $(P<0.001)$ and to $0.7 \pm 1.3$ at M3 $(P<0.001)$ in the switch group (Fig. 1b), without intergroup difference.

Physical activity, as self-assessed by patients, was improved in both groups (Fig. 2), as evidenced by a progressive increase from baseline to M1 and then to M3 in the proportion of patients who reported no limitation or slight limitation and by a progressive decrease in the

Table 3 Patient adherence to antianginal therapy

\begin{tabular}{|c|c|c|c|c|c|c|}
\hline & \multicolumn{3}{|c|}{ Initiation group, $n(\%)$} & \multicolumn{3}{|c|}{ Switch group, $n$ (\%) } \\
\hline & Baseline & M1 & M3 & Baseline & M1 & M3 \\
\hline Good adherence & 467 (25.4\%) & $705(38.3 \%)^{*}$ & $1003(54.5 \%)^{*, \#}$ & $260(21.4 \%)$ & $467(38.4 \%)^{*}$ & $711(58.6 \%)^{*, \#}$ \\
\hline Moderate adherence & $744(40.4 \%)$ & $993(54.0 \%)^{*}$ & $781(42.5 \%)^{\#}$ & $494(40.6 \%)$ & $650(53.5 \%)^{*}$ & $468(38.6 \%)^{\#}$ \\
\hline Non-adherence & $630(34.2 \%)$ & $142(7.7 \%)^{*}$ & $55(2.99 \%)^{*}$ & $462(38.0 \%)$ & $98(8.1 \%)^{*}$ & $35(2.9 \%)^{*}$ \\
\hline Total & $1841(100 \%)$ & $1841(100 \%)$ & $1839(100 \%)$ & $1216(100 \%)$ & $1215(100 \%)$ & $1214(100 \%)$ \\
\hline
\end{tabular}

M1 month 1, M3 month 3

${ }^{*} p<0.001$ vs. baseline
$p<0.001$ vs. M1 
proportion of patients who reported substantial limitation or very marked reduction.

Adherence to antianginal treatment improved significantly in both groups (Table 3 ). In the initiation group, good adherence was reported by $54 \%$ of patients at M3 vs. $25 \%$ at baseline $(p<0.001)$ and vs. $38 \%$ at M1 $(p<0.001)$. In the switch group, good adherence was reported by $59 \%$ of patients at M3 vs. $21 \%$ at baseline $(p<0.001)$ and vs. $38 \%$ at M1 $(p<0.001)$. Non-adherence decreased from $34 \%$ at baseline to $8 \%$ at M1 $(p<0.001)$ and further decreased to $3 \%$ at M3 $(p<0.001$ vs. baseline) in the initiation group. Similarly, in the switch group, the proportion of non-adherent patients decreased from $38 \%$ to $8 \%$ at M1 $(p<0.001)$ and to $3 \%$ at M3 ( $p<0.001$ vs baseline).

At the global assessment performed at the last visit, overall effectiveness of TMZ $80 \mathrm{mg}$ od was rated by physicians as "very good" $(67.8 \%$ in the initiation group vs. $69.8 \%$ in the switch group), "good" (30.7\% in the initiation group vs $29.5 \%$ in the switch group), "moderate" $(1.1 \%$ in the initiation group vs $0.7 \%$ in the switch group) or "poor" $(0.3 \%$ in the initiation group vs $0.1 \%$ in the switch group). Overall tolerability was rated by physicians as "very good" (75.2\% in both groups), "good" (24.7\% in the initiation group vs. $24.8 \%$ in the switch group) or "moderate" $(0.1 \%$ in the initiation group and $0 \%$ in the switch group).

\section{DISCUSSION}

In the present report, we examined the effect of the addition of TMZ $80 \mathrm{mg}$ od in two clinical situations: patients initiating treatment with TMZ $80 \mathrm{mg}$ od and patients switching to TMZ $80 \mathrm{mg}$ od from previous treatment with TMZ $20 \mathrm{mg}$ tid or TMZ $35 \mathrm{mg}$ MR bid. In both groups, we observed a significant decrease in angina attack frequency and in SAN consumption, as well as an improvement in CCS classification and in self-reported patient physical activity. These results are in line with the findings reported for the overall population of the ODA study [7]. Of note, the proportion of patients with CCS Class I increased by four times by M3 in both groups. Achievement of CCS Class I is very important for quality of life, which is one of the main objectives of antianginal treatment according to guidelines [9].

TMZ $80 \mathrm{mg}$ od has been shown in a randomized double-blind phase III study to have similar safety profile to TMZ MR $35 \mathrm{mg}$ bid [10] and was well tolerated in a real-world setting [7].

The mechanism of action of TMZ differs from that of other antianginal drugs. It targets directly myocardial cells, optimizing cellular energetics particularly under ischemic conditions [5], which makes it a valuable antianginal therapy regardless of the background medications [11]. The antianginal efficacy of TMZ has been shown in controlled trials in patients with stable angina treated with TMZ in monotherapy or as a part of combination therapy [12-16]. In monotherapy, the antianginal efficacy of TMZ was shown versus placebo [12]. TMZ was shown to have similar efficacy to other classes of antianginal drugs, such as diltiazem or propranolol $[13,14]$. In a meta-analysis that included 218 trials with a total of 19,028 patients, TMZ significantly improved exercise tolerance, weekly angina episodes and use of SAN compared with placebo. TMZ efficacy was comparable to that of other non-heart-rate-lowering antianginal treatments [6]. It has also been shown that increasing the number of hemodynamic drugs does not increase antianginal efficacy [15-18]. On the contrary, combining TMZ with hemodynamic agents (beta-blockers or long-acting nitrates) significantly improved exercise stress test parameters and angina symptoms, as demonstrated in the TACT study [19]. The TRIMPOL study also showed that treatment with metoprolol and trimetazidine led to significant improvement in exercise stress tests and angina symptoms compared to metoprolol and placebo [20]. Finally, in patients with stable effort-induced angina not sufficiently controlled with propranolol, the addition of trimetazidine led to better antianginal efficacy than addition of isosorbide dinitrate [21]. All these data provide evidence that TMZ is an efficacious therapy to improve angina control. The results of the present study provide 
additional evidence of the effectiveness of TMZ in a real-life setting, as initiation of TMZ $80 \mathrm{mg}$ od resulted in significant decrease in angina attacks and SAN consumption and improved functional status as assessed by CCS classification and physical activity.

Moreover, adherence to antianginal treatment was improved in the present study. The improvement in adherence observed when patients switched from TMZ bid or tid formulation to $\mathrm{TMZ}$ od formulation could be explained by treatment simplification, as adherence is inversely related to the number of medication doses to be taken per day [22]. However, as adherence was also improved in the initiation group, the increase in adherence could be related to the reduction in angina symptoms and the improvement in daily activity as perceived by patients. Moreover, we cannot exclude that participation to the trial could have had a beneficial effect on adherence.

The clinical implications of these findings are that TMZ addition provides a useful therapeutic strategy for clinicians, with regard to several aspects: antianginal effectiveness, adherence improvement, and patient-reported improvement with regard to their daily physical activity.

\section{Study Limitations}

The study has limitations inherent in the nature of its design (open-label, observational), which may have resulted in bias toward overestimating the treatment effect. Another limitation is the lack of a control group, which might have biased the results by overestimating the treatment effect. The short duration of follow-up (3 months) in this chronic condition is another limitation. Further investigations should be undertaken to confirm these results over a longer period of time. The tools used to test physical activity were not previously validated. Results are based on patient history and selfevaluation of angina and functional status, which can be a limitation. However, this allowed assessing the main objective of antianginal treatment, which is the reduction of symptoms and the improvement of quality of life.

\section{CONCLUSIONS}

In the present analysis of a prospective observational study over a 3-month period in daily clinical practice, TMZ $80 \mathrm{mg}$ od, in association with other antianginal therapy, effectively reduced angina attacks and nitrate consumption and improved daily physical activity, CCS class and self-reported adherence to antianginal treatment both in patients initiating TMZ treatment and in those switching from a bid or tid formulation.

\section{ACKNOWLEDGEMENTS}

The authors would like to thank the participants of the study.

Funding. Sponsorship for this study was provided by Servier, Moscow, Russian Federation. Editorial assistance and article processing charges were funded by Servier, France. All authors had full access to all of the data in this study and take complete responsibility for the integrity of the data and accuracy of the data analysis.

Medical Writing and Editorial Assistance. Writing and editorial assistance was provided by Dr. Diana Toli (Servier) and funded by Servier, France.

Authorship. All named authors meet the International Committee of Medical Journal Editors (ICMJE) criteria for authorship for this article, take responsibility for the integrity of the work as a whole, and have given their approval for this version to be published.

List of Investigators. The full list of ODA study investigators is available in the supplementary material.

Prior Presentation. The data presented in this manuscript have been previously presented as a poster at the congress of the European Society of Cardiology (ESC) in 2018. 
Disclosures. Maria G. Glezer, scientific coordinator of this study, received honoraria for lectures from Servier, Moscow, Russian Federation. Vladimir A. Vygodin has nothing to disclose.

Compliance with Ethics Guidelines. All procedures performed in studies involving human participants were in accordance with the ethical standards of the institutional and/or national research committee and with the 1964 Helsinki Declaration and its later amendments or comparable ethical standards. Informed consent was obtained from all individual participants included in the study. This study was approved by the Interuniversity Ethical Committee, Moscow.

Data Availability. The datasets during and/ or analyzed during the current study are available from the corresponding author on reasonable request.

Open Access. This article is distributed under the terms of the Creative Commons Attribution-NonCommercial 4.0 International License (http://creativecommons.org/licenses/ by-nc/4.0/), which permits any noncommercial use, distribution, and reproduction in any medium, provided you give appropriate credit to the original author(s) and the source, provide a link to the Creative Commons license, and indicate if changes were made.

\section{REFERENCES}

1. Moran AE, Forouzanfar MH, Roth GA, et al. The global burden of ischemic heart disease in 1990 and 2010: the Global Burden of Disease 2010 study. Circulation. 2014;129:1493-501.

2. Beltrame JF, Weekes AJ, Morgan C, Tavella R, Spertus JA. The prevalence of weekly angina among patients with chronic stable angina in primary care practices: the Coronary Artery Disease in General Practice (CADENCE) Study. Arch Intern Med. 2009;169:1491-9.

3. Kureshi F, Shafiq A, Arnold SV, et al. The prevalence and management of angina among patients with chronic coronary artery disease across US outpatient cardiology practices: insights from the Angina Prevalence and Provider Evaluation of Angina Relief (APPEAR) study. Clin Cardiol. 2017;40:6-10.

4. Qintar M, Spertus JA, Gosch KL, et al. Effect of angina under-recognition on treatment in outpatients with stable ischaemic heart disease. Eur Heart J Qual Care Clin Outcomes. 2016;2:208-14.

5. Fragasso G, Perseghin G, De Cobelli F, et al. Effects of metabolic modulation by trimetazidine on left ventricular function and phosphocreatine/adenosine triphosphate ratio in patients with heart failure. Eur Heart J. 2006;27:942-8.

6. Danchin N, Marzilli M, Parkhomenko A, Ribeiro JP. Efficacy comparison of trimetazidine with therapeutic alternatives in stable angina pectoris: a network meta-analysis. Cardiology. 2011;120:59-72.

7. Glezer MG, Vygodin VA; ODA investigators. Antianginal effectiveness and tolerability of trimetazidine modified release $80 \mathrm{mg}$ once daily in stable angina patients in real-world practice. Adv Ther. 2018; 35:1368-1377.

8. Girerd X, Radauceanu A, Achard JM, et al. Evaluation of patient compliance among hypertensive patients treated by specialists. Arch Mal Coeur Vaiss. 2001; 94: 839-42 (Article in French).

9. Montalescot G, Sechtem U, Achenbach S, et al. 2013 ESC guidelines on the management of stable coronary artery disease: the Task Force on the management of stable coronary artery disease of the European Society of Cardiology. Eur Heart J. 2013;34:2949-3003.

10. Pozdnyakov YM; study investigators. Clinical acceptability of trimetazidine modified-release $80 \mathrm{mg}$ once daily versus trimetazidine modified-release $35 \mathrm{mg}$ twice daily in stable angina pectoris. Cardiol Ther. 2018;7:61-70.

11. Glezer M; CHOICE-2 study investigators. The effectiveness of trimetazidine treatment in patients with stable angina pectoris of various durations: results from the CHOICE-2 Study. Adv Ther 2018; 35:1103-1113.

12. Passeron J. Effectiveness of trimetazidine in stable effort angina due to chronic coronary insufficiency. A double-blind versus placebo study. Presse Med. 1986;15:1775-1778.

13. Koylan N, Bilge AK, Adalet $\mathrm{K}$, Mercanoglu F, Buyukozturk K. Comparison of the effects of trimetazidine and diltiazem on exercise performance in patients with coronary heart disease. The Turkish trimetazidine study (TTS). Acta Cardiol. 2004;59: 644-650. 
14. Detry JM, Sellier P, Pennaforte S, Cokkinos D, Dargie $\mathrm{H}$, Mathes $\mathrm{P}$. Trimetazidine: a new concept in the treatment of angina. Comparison with propranolol in patients with stable angina. Trimetazidine European Multicenter Study Group. Br J Clin Pharmacol. 1994;37:279-288.

15. Fox KM, Mulcahy D, Findlay I, Ford I, Dargie HJ. The Total Ischaemic Burden European Trial (TIBET). Effects of atenolol, nifedipine SR and their combination on the exercise test and the total ischaemic burden in 608 patients with stable angina. The TIBET Study Group. Eur Heart J. 1996; 17:96-103.

16. Pehrsson SK, Ringqvist I, Ekdahl S, Karlson BW, Ulvenstam G, Persson S. Monotherapy with amlodipine or atenolol versus their combination in stable angina pectoris. Clin Cardiol. 2000;23:763-70.

17. Madjlessi-Simon T, Fillette F, Mary-Krause M, Lechat P, Jaillon P. Effects of amlodipine on transient myocardial ischaemia in patients with a severe coronary condition treated with a beta-blocker. Amlor-Holter Study Investigators. Eur Heart J. 1995;16:1780-8.

18. Savonitto S, Ardissiono D, Egstrup K, Rasmussen K, Bae EA, Omland T, Schjelderup-Mathiesen PM, Marraccini P, Wahlqvist I, Merlini PA, Rehnqvist N. Combination therapy with metoprolol and nifedipine versus monotherapy in patients with stable angina pectoris. Results of the International Multicenter Angina Exercise (IMAGE) Study. J Am Coll Cardiol. 1996;27:311-6.

19. Chazov EI, Lepakchin VK, Zharova EA, et al. Trimetazidine in Angina Combination Therapy-the TACT study: trimetazidine versus conventional treatment in patients with stable angina pectoris in a randomized, placebo-controlled, multicenter study. Am J Ther. 2005;12:35-42.

20. Szwed H, Sadowski Z, Elikowski W, et al. Combination treatment in stable effort angina using trimetazidine and metoprolol: results of a randomized, double-blind, multicentre study (TRIMPOL II). TRIMetazidine in POLand. Eur Heart J. 2001;22:2267-74.

21. Michaelides A, Spiropoulos K, Dimopoulos K, Athanasiades D, Toutouzas P. Antianginal efficacy of the combination of trimetazidine-propranolol compared with isosorbide dinitrate-propranolol in patients with stable angina. Clin Drug Invest. $1997 ; 13: 8-14$.

22. Claxton AJ, Cramer J, Pierce C. A systematic review of the associations between dose regimens and medication compliance. Clin Ther. 2001;23:1296-310. 